International Journal of Dairy Processing \& Research (JDPR)

\title{
Influence of Goat Milk on Iron Deficiency Anemia Recovery
}

Díaz-Castro $\mathrm{J}^{1,2^{*}}$, Lisbona $\mathrm{F}^{2}$, Moreno $\mathrm{M}^{2}$, Alférez $\mathrm{MJM}^{2}$, Campos $\mathrm{MS}^{1,2}$, López-Aliaga I,2

${ }^{1}$ Institute of Nutrition and Food Technology "José Mataix Verdú”. Biomedical Research Center. Health Sciences Technological Park. University of Granada, 18071, Granada, Spain.

${ }^{2}$ Department of Physiology. Faculty of Pharmacy. Campus de Cartuja, s/n. University of Granada, 18071, Granada, Spain.

\begin{abstract}
Despite Fe deficiency and overload having been widely studied, researchers are still looking for natural foods with beneficial nutritional characteristics which can help to palliate or recover this highly prevalent nutritional deficiency. In this sense, goat milk is a natural food with beneficial nutritional characteristics which can help to reach these goals. Goat milk consumption leads to a better recovery of body Fe stores, minimizing Ca-Fe interactions and improving Fe status and its absorption and increases the $\mathrm{Cu}$ bioavailability, an essential mineral for erythropoiesis. In addition, goat milk consumption improves DNA stability, due to the quality its fat, together with the high levels of bioavailable $\mathrm{Mg}$ and $\mathrm{Zn}$, even during chronic Fe-overload. Caprine milk also has positive effects on antioxidant defence, even in a situation of Fe overload, limiting lipid peroxidation and improving antioxidant status. Finally improves bone turnover, impaired by Fe-deficiency, increasing bone formation and diminishing parathorme levels. Therefore, inclusion of goat milk is recommended in the diet of people, who suffer nutritional Fe deficiency anemia, since this type of milk helps to relieve the adverse effects produced in bone turnover, oxidative stress and mineral bioavailability due to the Fe deficiency.
\end{abstract}

\section{*Corresponding Author:}

Javier Díaz-Castro,

Departament of Physiology and Institute of Nutrition and Food Technology, University of Granada, Biomedical Research Centre, Health Sciences Technological Park, Avenida del Conocimiento s/n, Armilla, 18071 Granada, Spain.

Tel: +34958241000 extn.: 20303

E-mail: javierdc@ugr.es

Recieved: January 20, 2015

Accepted: January 24, 2015

Published: February 25, 2015

Citation: Díaz-Castro J et al., (2015) Influence of Goat Milk on Iron Deficiency Anemia Recovery. Int J Dairy Process Res. 2(1), 7-11. doi: http://dx.doi.org/10.19070/2379-1578-150003

Copyright: Díaz-Castro J ${ }^{\circ}$ 2015. This is an open-access article distributed under the terms of the Creative Commons Attribution License, which permits unrestricted use, distribution and reproduction in any medium, provided the original author and source are credited.

\section{Introduction}

Iron deficiency is the most widespread nutritional deficiency in the world. It is the most common cause of anemia during pregnancy. Iron deficiency of nutritional origin is the most frequent cause of microcytic hypochromic anemia, but other conditions such as bleeding, gastro-intestinal malabsorption, Helicobacter pylori infection, malaria, hookworm infections, and schistosomiasis can lead to iron deficiency and anemia. Iron restricted erythropoiesis underlies the anemia of chronic diseases, although several other mechanisms such as suppressed erythropoiesis and poor response to erythropoietin also contribute to this form of anemia [1]. It estimated than $30 \%-50 \%$ of anemia in children and other groups are caused by iron deficiency [2]. Because 1.6 billion people are anemic [3], several hundred million manifest iron deficiency anemia. As such, iron deficiency is the most common cause of anemia worldwide. Iron deficiency anemia afflicts a subset of the two billion people worldwide who are nutritionally iron deficient [4]. Therefore, the health burden of iron deficiency may be extrapolated from the global prevalence of anemia.

Local economics generally dictate the level of nutrition worldwide. The diet, by itself, infrequently causes iron deficiency anemia in the absence of severe malnourishment or a comorbidity. A balanced diet is usually sufficient to prevent anemia, however, the diet becomes far more relevant when the iron stores are lost, or anemia has already developed, and the host requires additional iron absorption from the gut for recovery [5]. This occurs especially during blood loss, rapid growth during infancy, malaria, and hookworm. In these settings, the diet and iron supplements become critical for maintaining iron availability. Supplemental dietary iron may be needed, because the average Western diet is not sufficient to meet the needs during pregnancy [6]. In addition to the iron content itself, the bioavailability of iron for absorption depends largely on the dietary components [7]. Iron in the form of heme is especially bioavailable, and meat-containing diets are also beneficial [8]. Vitamin C improves dietary availability of iron as well as avoidance of tea or other iron-chelating substances [9]. Numerous approaches are being tried to improve iron availability in the diet with the goal of low-cost and culturally acceptable implementation among the underprivileged [10]. In this sense, as discussed in the current review, goat milk is a natural food with beneficial nutritional characteristics which can help to palliate or recover this highly prevalent nutritional deficiency. 


\section{Goat Milk}

Dairy goat and dairy sheep farming are a vital part of the national economy in many countries, especially in the Mediterranean and Middle-East region and are particularly well organized in France, Italy, Spain and Greece [11]. Goat milk is wanted or even needed by people of all income groups. Despite the much larger volume available of cow milk, it's usually cheaper production and therefore, lower market price, the production and marketing of goat milk and its products is therefore, an essential niche in the total dairy industry sector. Goat milk differs from cow or human milk in having better digestibility, alkalinity, buffering capacity and certain therapeutic values in medicine and human nutrition $[12,13]$. Goat milk has been studied as a natural food with excellent nutritional properties. Although the consumption of goat milk and its products is currently low, its acceptance is rising with the current trend in favor of high quality, nutritious and healthy foods [14]. The importance of goat milk as a food resides in its high digestibility and nutritional value, as well as its therapeutic and dietary characteristics $[15,16]$.

Caprine milk is an excellent source of high quality protein, easily absorbed [17] and more digestible than cow milk due to smaller fat globule size and higher contents of short- and medium-chain fatty acids [18]. The smaller-sized fat globules provide a better dispersion and a more homogeneous mixture of fat in the milk, and their larger surface area enhances further pancreatic lipase activity, making goat milk easier to digest $[14,19]$. Goat milk has a high proportion of short- and medium-chain saturated fatty acids, such as butyric (C4:0), caproic (C6:0), caprylic (C8:0) and capric (C10:0), and long-chain mono- and polyunsaturated fatty acids [18]. The fat sources of medium-chain triglycerides (MCT) may be advantageous under certain circumstances since they are absorbed intact and do not undergo degradation and reesterification processes. MCT are more readily hydrolyzed by pancreatic enzymes than is long-chain triglyceride fat. Micelle formation is not required for absorption, since the molecules are taken up directly into the portal vein. The fatty acids within MCT penetrate the mitochondria of hepatic cells, independently of carnitine acylCoA transferase $[20,21]$. Thus they contribute to easier, faster digestion, a feature which makes them especially suitable for post-resection feeding. Finally, these MCT fatty acids are oxidized to produce a rapid energy discharge that can be used in various metabolic processes and produce lower deposits of fat within the organism [18]. In addition, weight gain was improved with goat milk in the diet, compared to cow milk, and levels of cholesterol were reduced, while triglyceride, High Density Lipoproteins values remained normal [22]. It was concluded that the consumption of goat milk reduces total cholesterol levels and the Low Density Lipoproteins fraction because of the higher presence MCT $36 \%$ in goat milk versus $21 \%$ in cow milk), which decreases the synthesis of endogenous cholesterol.

Noteworthy minerals include calcium and phosphorus, which feature high digestibility levels, partly because they are associated with milk casein and also are present in optimum proportions for absorption (Ca:P 1.0:1.5). Goat milk as a substitute for cow milk was studied in 38 children during a 5 months period [23]. The children on goat milk surpassed those on cow milk in weight gain, height, skeletal mineralization, and blood serum contents of vitamin A, calcium, thiamin, riboflavin, niacin and hemoglobin. Therefore, goat milk supplies adequate amounts of vitamin A, thiamine, riboflavin and pantothenic acid. The only negative as- pect of the composition of goat milk concerns its low content of folic acid $[18,24]$ and vitamin $B_{12}[18,25]$. Goat milk, taking into account its nutrient content, constitutes an alternative to cow milk that is highly beneficial in certain aspects of human nutrition, especially for children. Many of the adverse reactions that may be produced by consuming cow milk, and especially those concerning certain protein fractions, as well as lactose intolerance, can often be avoided by substituting it with goat milk [18]. Hence, goat milk is recommended for infants, old and convalescent people. In addition to this, fatty acids like caproic, caprylic and capric are reported to have great medicinal values for patients suffering from a variety of malabsorption, childhood epilepsy, cystic fibrosis, gallstones [26] and anemia [27].

\section{Influence of Dietary Goat Consumption on Ane- mia Recovery}

\section{Influence of Dietary Goat Consumption on Iron Metabo- lism}

In a study by Nestares et al. [28], the authors reported that with goat milk there is a better recovery of body Fe stores in anemic rats, despite Ca-supplementation. In this study it is noteworthy that despite high $\mathrm{Ca}$ content, a goat milk diet resulted in minimal $\mathrm{Ca}-\mathrm{Fe}$ interactions and did not adversely affect Fe status in rats with Fe-deficiency anemia, improving nutritive Fe utilization. The greater nutritive utilization of $\mathrm{Fe}$ found with goat milk, could be due to various nutritional factors; goats' milk fat is richer in MCT than the fat obtained from cows' milk, 36 vs. $21 \%$, [22]. The MCT in the diet are oxidized, providing fast energy discharge that can be used in several metabolic pathways [21] and thus contribute to increasing the synthesis of carrier proteins and hence Fe absorption

Numerous dietary components, present in greater quantities in goat milk than in cow milk [27], are capable of reducing Fe (III) to Fe (II), including ascorbic acid [29], and amino acids such as lysine [30] and cysteine [31]. In addition, goat milk has almost twice the vitamin A content than cow milk [27], vitamin that may mobilize available Fe stores and use them to form hemoglobin [32]. On the other hand, the b-carotene improves Fe uptake and overcomes the inhibition by potent inhibitors of Fe absorption [33]. Goats' milk also has higher vitamin D content than cows' milk [27], promoter of the active component in the absorptive process of Fe which has been reported previously [34]. The protein of goat milk is more soluble than that of cow milk and contains a higher proportion of other soluble proteins ( $\beta$-lactoglobulin, $\alpha$-lactoalbumin and serum albumin). The proteins offered by goat milk usually have a lower proportion of caseins and consequently a higher quantity of soluble serum proteins. This fact, together with their animal origin [35], could lead to higher absorption of these proteins and thus favor Fe utilization.

\section{Influence of Dietary Goat Consumption on Copper Metabo- lism During Anemia Recovery}

Goat's milk has greater MCT content than cow's milk [27], and these fatty acids favor the intestinal transport of nutrients (including $\mathrm{Cu}$ ), because they have a trophic effect on the small intestine, improving uptake and transport through the enterocyte basolateral membrane [36]. MCT are absorbed without re-esterification and directly enter portal circulation where they can be 
metabolized to obtain energy. Fe-deficiency anemia enhances the digestive and metabolic utilization of $\mathrm{Cu}$, because a deficiency of divalent Fe cations in the intestine can increase the absorption of other divalent cations, including $\mathrm{Cu}$ [37].

Some studies on isolated epithelial cells, suggest that the main intestinal Fe transporter DMT1 (divalent metal transporter 1) can also transport $\mathrm{Cu}$ across the apical membrane $[38,39]$ and this transporter could be regulated by both $\mathrm{Fe}$ and $\mathrm{Cu}$ [38]. Extended periods of iron deficiency could lead to an up-regulation of DMT1 expression which subsequently produces an increase in $\mathrm{Cu}$ absorption in $\mathrm{Fe}$ deficient animals. In addition, Gómez-Ayala et al. [34] showed that in Fe deficiency, $\mathrm{Cu}$ absorption increases. Dietary $\mathrm{Cu}$ is acquired via the small intestine through a process that is not fully understood, but earlier studies showing the major involvement of the mammalian transporter Copper Transport Protein 1 (CTR1) in cellular copper uptake led to the assumption that in enterocytes CTR1 mediates the acquisition of dietary copper at the apical membrane [40]. This $\mathrm{Cu}$ transporter is specific for $\mathrm{Cu}$, and $\mathrm{Fe}$ is therefore not expected to interfere with $\mathrm{Cu}$ absorption, so CTR1 could not be involved in the increase in $\mathrm{Cu}$ absorption in situation of Fe deficiency. On the other hand, Domellöf et al. [41] found that Fe supplementation does not affect $\mathrm{Cu}$ absorption in breastfed infants.

Adequate dietary $\mathrm{Cu}$ intake and absorption is essential for efficient absorption and utilization of dietary Fe. Reeves and DeMars [42] found that $\mathrm{Cu}$-deficient animal models retained less dietary $59 \mathrm{Fe}$ than $\mathrm{Cu}$-adequate rats using whole-body $59 \mathrm{Fe}$ counting. $\mathrm{Cu}$ facilitates intestinal $\mathrm{Fe}$ absorption by promoting $\mathrm{Cu}$-dependent ferroxidase (hephaestin) activity in the duodenal enterocyte. Signs of Fe deficiency such as low serum Fe and anemia appear in weaning rats within a few days of consuming a Cu-deficient diet [43]. This finding suggests a very important role for $\mathrm{Cu}$ in $\mathrm{Fe}$ absorption. In addition, $\mathrm{Cu}$ affects the $\mathrm{Cu}$-dependent ferroxidase activity of ceruloplasmin, a plasma enzyme that catalyzes the oxidation of ferrous ion into the ferric ion required for hemoglobin synthesis. Afterwards, hemoglobin is transported from hepatic stores to the bone marrow to be used in erythropoiesis [44]. Cu-deficient rats are anemic and ceruloplasmin activity is reduced to near zero [42].

Comparison of both milk shows that the Cu content in sternum, kidney, spleen, and heart is higher for both the control and Fe-deficient animals fed on the goat's milk compared to the cow's milk diet. Moreover, $\mathrm{Cu}$ in the kidney was two-fold higher when iron deficient rats were given the Ca-fortified goat's milk, as compared to a cow's milk diet. Goat's milk diets, with both normal $\mathrm{Ca}$ and elevated $\mathrm{Ca}$, favored higher $\mathrm{Cu}$ deposition in the sternum, kidney, spleen, and heart in comparison to the cow's milk diet. This fact is probably a consequence of higher $\mathrm{Cu}$ absorption and retention as indicated above. For all groups, the highest concentration of $\mathrm{Cu}$ was found in the kidneys. This result is in agreement with a report by Linder [45] who showed that $\mathrm{Cu}$ distribution throughout the organism is accomplished in two phases. The first phase involves the transfer of $\mathrm{Cu}$ from the intestine to the liver and the kidneys, and the second phase involves distribution from the liver to the other organs. The kidney is rich in $\mathrm{Cu}$, and as has been shown by Barrionuevo et al. [46] this organ consistently reflects $\mathrm{Cu}$ absorption and metabolism. However, in this study the renal copper concentration did not always reflect $\mathrm{Cu}$ absorption and metabolism.

Whereas goat's milk diet fortified with Ca raised the quantity of $\mathrm{Cu}$ deposited in the sternum in the Fe-deficient animals, the con- trary effect was observed with the cow's milk diet; it can be related with the negative effect of $\mathrm{Ca}$ fortification on $\mathrm{Cu}$ retention with the cow's milk diet, whereas with the goat's milk diet $\mathrm{Cu}$ retention is not affected. Moreover, this finding of elevated $\mathrm{Cu}$ in the sternum and spleen may be very important because this is a required mineral in the formation of erythrocytes [44], and these are important organs in the erythrocyte life cycle.

\section{Influence Of Dietary Goat And Cow Milk On Bone Turno- ver During Anemia Recovery}

Díaz-Castro et al. [47] reported that in severe Fe-deficiency, bone matrix formation diminished as revealed by the lower amount of procollagen type I N-terminal propeptide and bone resorption process increased as shown by the increase of serum parathyroid hormone, tartrate-resistant acid phosphatase and levels of degradation products from C-terminal telopeptides of type I collagen released to the serum. In addition, mineralization process was also affected by Fe deficiency, because $\mathrm{Ca}$ and $\mathrm{P}$ content in femur decreased markedly.

Diaz-Castro et al. [48] reported that in only 10 days of supplying goat milk, bone demineralization induced by Fe deficiency begins to recover, as evidenced by the increase of the bone formation biomarker Procollagen type I N-terminal propeptide (PINP) and diminishing parathormone levels. If the consumption of milkbased diets is more prolonged ( 30 or 50 days), the parameters of bone remodeling recover with both milk-based diets, though the goat milk restores before this process and favors the mineralization of femur and sternum, improving bone metabolism and hematopoietic process. The beneficial effect of goat milk on mineral metabolism has been well documented, improving Fe bioavailability $[27,28]$, which becomes available in the hydroxylation processes and then in the biosynthesis of the vitamin D. It is well known that 25 - hydroxycholcalciferol-1-hydroxylase is located within the renal mitochondria and this enzyme is Fe-dependent. Moreover, Fe exerts its influence on bone turnover by affecting type I collagen synthesis and maturation. Fe is an essential cofactor for prolyl and lysyl hydroxylases, enzymes that catalyze an ascorbate-dependent hydroxylation of prolyl and lysyl residues, essential steps prior to crosslinking by lysyl oxidase. Therefore, an improvement in Fe bioavailability would contribute to increase cross-linking activity and, subsequently, stronger collagen fibers. This fact supports the increase in the PINP found in animals fed with goat milk-based diets, reflecting faithfully the higher amount of bone matrix developed. With regard to PTH levels, the supply of goat milk during 10 days, produced a decrease of this hormone in the anemic animals, and an increase in those who consumed cow milk. These results can be explained by the increase in nutritive utilization of $\mathrm{Ca}$, consequence of the greater absorption of this mineral, as previously reported Campos et al. [49]. According to Hale et al. [50], PINP levels can be correlated directly with PTH levels and recent studies reveal that at intermittent doses and within the physiological range, the PTH favors the bone formation through an increase of the number of osteoblasts [51], since the PTH stimulates the transformation of osteocites in osteoblasts [52] and diminishes the apoptosis of these cells [53].

\section{Influence Of Dietary Goat Milk On Oxidative Stress During Anemia Recovery}

As a result of the regular cell metabolism, the anion superoxide $\left(\mathrm{O}_{2}^{*}\right)$ is converted into $\mathrm{H}_{2} \mathrm{O}_{2}$ by the ubiquitous enzyme superox- 
ide dismutase (SOD). Later, $\mathrm{H}_{2} \mathrm{O}_{2}$ produced in this reaction is converted into harmless compounds by the activities of catalase (CAT) and glutathione peroxidase (GPx); therefore, SOD is the first line of enzymatic defence against free radicals. During anemia recovery, Díaz-Castro et al. [47] recorded an increased activity of SOD in the groups fed the cow milk-based diet, revealing that these animals feature a higher generation of radicals $\mathrm{O}_{2}{ }^{-}$than those fed the goat milk-based diet, either with normal Fe content or Fe overload, in all the organs studied, which indicates an increase in the production of $\mathrm{H}_{2} \mathrm{O}_{2}$, directly correlated with the rate of neutralisation of radicals $\mathrm{O}_{2} \cdot$. Alférez et al. [54] and Díaz-Castro et al. [55] demonstrated that goat milk consumption improves $\mathrm{Zn}$ bioavailability, a mineral with antioxidant capacity [56]. In addition, this type of milk has a better lipid quality than cows' milk [22]; therefore, the generation of free radicals is lower when goat milk is supplied, in comparison with cows' milk, which can be linked to the higher rate of lipid peroxidation achieved in animals fed cows' milk. Díaz-Castro et al. [47] also showed that the slightly modified activity of CAT and GPx in animals fed the cow milk based-diet indicates that the remarkable increase observed in SOD, which is shown to be connected to an increment of the formation of hydroperoxides and CAT and GPx, is insufficient to neutralize and scavenge this high output of $\mathrm{H}_{2} \mathrm{O}_{2}$. Fe overload increases the production of reactive oxygen species, which is linked to the higher levels of SOD in order to remove the excessive production of $\mathrm{O}_{2}^{-}$. The increase in thiobarbituric acid-reactive substances (TBARS) is more pronounced in animals receiving the cow milk that in those fed the goat milk. This lower trend to prevent lipid peroxidation in animals fed the goat milkbased diet can be due to the beneficial nutritional characteristics of this type of milk that increases the bioavailability of antioxidant minerals, such as $\mathrm{Zn}[54,55]$. Several metals may interact with $\mathrm{Zn}$ in biological systems, and this interaction could have beneficial effects, preventing undesirable Fe-mediated damage, so $\mathrm{Zn}$ can replace $\mathrm{Fe}$ and reduce oxidation in the plasma membrane. Moreover, $\mathrm{Zn}$ could avoid lipid peroxidation because this mineral competes with Fe for binding sites on the cell membrane [56]. On the other hand, the better nutritive utilisation of goat milk fat [22] provides a lower substrate for lipid peroxidation and consequently decreases the generation of free radicals in animals consuming this type of milk, explaining once more the lower TBARS levels found in the groups consuming the goat milk.

Díaz-Castro et al. [57] have also reported the positive role on genomic stability of the habitual consumption of goat milk, even during Fe-overloading feeding regime, fact that could be due, at least in part to the high bioavailability of $\mathrm{Mg}$ [28] and $\mathrm{Zn}$ [55], together with its better fat quality [22]. Mg metabolism enhances genomic stability because of the following: DNA is continuously damaged by environmental mutagens and by endogenous processes. To keep mutation frequencies low, cells have evolved different types of DNA repair systems. Nucleotide excision repair is mainly involved in the removal of DNA damage induced by environmental mutagens, and $\mathrm{Mg}$ is an essential cofactor in virtually all steps of nucleotide excision repair [58]. Secondly, endogenous DNA damage is mainly repaired by base excision repair (BER). According to current models, BER is initiated by the removal of the modified base by a specific N-glycosylase, an enzyme that is activated mainly by $\mathrm{Mg}$ [59]. The third DNA repair system is the mismatch-repair pathway which contributes greatly to genomic stability by correcting replication errors [60]. It has been suggested that the enzymatic activity of MutS and MutL may play a role in switching from a mismatch-repair initiation to a processing complex. It has however been shown that MutL has an absolute requirement for $\mathrm{Mg}$; in the absence of $\mathrm{Mg}$, the MutL-ATP association is abolished completely [61]. Moreover, $\mathrm{Mg}$ is also required for double-strand break repair [62]. On the other hand, Díaz-Castro et al. [55] reported that the bioavailability of $\mathrm{Zn}$ is enhanced by goat milk when compared to cows' milk. This improvement in $\mathrm{Zn}$ metabolism could contribute to the protective effect of goat milk on DNA against oxidative damage. Moreover, the high quality of the goat milk fat would contribute to its positive effect on DNA stability. In this regard, as previously reported [22] goat milk fat is nutritionally superior that of cow milk. It has a higher content of carnitine that enters the mitochondria, to increase the rate of $\beta$-oxidation [63]. Moreover, goat milk has a high carnitine content, which certainly would increase the energy production derived from fatty acids and so the substrate for lipid peroxidation would be lower, consequently reducing free radicals production with this type of milk, that may have a positive influence on the stability of the DNA

\section{Conclusion}

The goat milk improves Fe metabolism, favoring the recovery of the Fe-deficiency anemia. In addition, it has positive effects on $\mathrm{Cu}$ metabolism, the evoked oxidative stress and bone turnover during the anemia recovery. In the light of these considerations, it is recommended that this natural food should be included in the diet of the general population and especially in that of people suffering from Fe-deficiency anemia.

\section{References}

[1]. De Falco L, Sanchez M, Silvestri L, Kannengiesser C, Muckenthaler MU et al. (2013) Iron refractory iron deficiency anemia. Hematologica, 98:845853.

[2]. World Health Organization. (2007) Conclusions and recommendations of the WHO consultation on prevention and control of iron deficiency in infants and young children in malaria-endemic areas. Food Nutr Bull 28: S621-S627.

[3]. McLean E, Cogswell M, Egli I, Wojdyla D, de Benoist B. (2009) Worldwide prevalence of anaemia, WHO Vitamin and Mineral Nutrition Information System, 1993-2005. Public Health Nutr 12: 444-454.

[4]. Viteri FE. (1998) A new concept in the control of iron deficiency: Community-based preventive supplementation of at-risk groups by the weekly intake of iron supplements. Biomed Environ Sci 11: 46-60.

[5]. Miller JL. (2013) Iron deficiency anemia: a common and curable disease. Cold Spring Harb Perspect Med 3: a011866.

[6]. Lee AI, Okam MM. (2011) Anemia in pregnancy. Hematol Oncol Clin North Am 25: 241-259.

[7]. Sharp PA. (2010) Intestinal iron absorption: Regulation by dietary and systemic factors. Int J Vitam Nutr Res 80: 231-242.

[8]. López MA, Martos FC (2004) Iron availability: An updated review. Int J Food Sci Nutr 55: 597-606.

[9]. Thankachan P, Walczyk T, Muthayya S, Kurpad AV, Hurrell RF. (2008) Iron absorption in young Indian women: The interaction of iron status with the influence of tea and ascorbic acid. Am J Clin Nutr 87: 881-886.

[10]. Hurrell RF, Lynch S, Bothwell T, Cori H, Glahn R, Hertrampf E, et al. (2004) Enhancing the absorption of fortification iron. A sustain task force report. Int J Vitam Nutr Res 74: 387-401.

[11]. Chiofalo BL, Liotta A, Zumbo A, Chiofalo V (2004) Administration of olive cake for ewe feeding: effect on milk yield and composition. Small Rumin Res 55:169-176.

[12]. Coni E, Bocca B, Caroli S (1999) Minor and trace element content of two typical Italian sheep dairy products. J Dairy Res 66:589-598.

[13]. Kumar S, Kumar B, Kumar R, Kumar S, Khatkar SK et al. (2012) Nutritional features of goat milk. A Review. Indian J Dairy Sci 65:266-273.

[14]. Chandan RC, Attaie R, Sahani KM (1992) Nutritional aspects of goat's milk and its products. Proceedings of 5th International Conference on Goats, New Delhi, India, vol. 2, part 2, pp. 399-420.

[15]. Haenlein GFW Goat milk in human nutrition. (2004) Small Rumin Res 
51: 155-163.

[16]. López-Aliaga I, Díaz-Castro J, Alférez MJM Barrionuevo M, Campos MS (2010) A review of the nutritional and health aspects of goat milk in cases of intestinal resection. Dairy Science and Technology 90: 611-622.

[17]. Park YW (1994) Hypo-allergenic and therapeutic significance of goat milk, Small Rumin Res 14: 151-159.

[18]. Park YW (2006) Goat milk-chemistry and nutrition, Park YW, Haenlein GFW Editors Handbook of milk of non-bovine mammals, Blackwell Publishing, Oxford, UK, pp. 34-58.

[19]. Jandal JM (1996) Comparative aspects of goat and sheep milk. Small Rumin Res 22: 177-185.

[20]. Velázquez OC, Seto RW, Rombeau JL (1996) The scientific rationale and clinical application of short-chain fatty acids and mediumchain triglycerides. Proc Nutr Soc 55: 49-78.

[21]. Matsuo T, Takeuchi H (2004) Effects of structural medium- and long-chain triglycerides in diets with various levels of fat on body fat accumulation in rats. Br J Nutr 91: 219-225.

[22]. Alférez MJM, Barrionuevo M, López-Aliaga I, Sanz Sampelayo MR, Lisbona F, et al. (2001) Digestive utilization of goat and cow milk fat in malabsorption syndrome. J Dairy Res 68:451-461.

[23]. Mack PB (1952) A preliminary nutrition study of the value of goat's milk in the diet of children. Year book. American Goat Society Publishers, Mena, Arkansas, USA, pp. 106-132.

[24]. Becroft DMO, Holland JT (1996) Goat's milk and megaloblastic anaemia of infancy. N Z Med J 65: 303-307.

[25]. Jauber O, Kalantzopoulos O (1996) Quality of goat milk for cheese and other products. Proceedings of the 6th International Conference on Goats, vol. 1, International Academic Publishers, Beijing, China, pp. 274-284.

[26]. Haenlein GFW (1992) Role of goat meat and milk in human nutrition. Proceedings of the Fifth International Conference on Goats, vol. II, part II. Indian Council of Agricultural Research Publishers, New Delhi, India, pp. 575-580.

[27]. Alférez MJM, López-Aliaga I, Nestares T, Díaz-Castro J, Barrionuevo M, et al. (2006) Dietary goat's milk improves Fe bioavailability in rats with induced ferropenic anemia in comparison with cow's milk. Int Dairy J 16: 813-818.

[28]. Nestares T, Díaz-Castro J, Alférez MJM, López Aliaga I, Barrionuevo M, et al. (2008) Calcium-enriched goat milk, in comparison with similarly enriched cow milk, favours magnesium bioavailability in rats with nutritional ferropenic anaemia. J Sci Food Agric 88:319-327.

[29]. Wienk KJ, Marx JJ, Beynen AC (1999) The concept of iron bioavailability and its assessment. Eur J Nutr 38: 51-75.

[30]. Van Campen, D R (1973) Enhancement of iron absorption from ligated segments of rat intestine by histidine, cysteine and lysine: Effects of removing ionizing groups and of steroisomerism. J Nutr 103: 139-142.

[31]. Glahn RP, Van Campen, DR (1997) Iron uptake is enhanced in Caco-2 cell monolayers by cysteine and reduced cysteinyl glycine. J Nutr 127: 642-647.

[32]. Bloem MW (1995) Interdependence of vitamin A and iron: an important association for programmes of anaemia control. Proc Nutr Soc 54: 501-508.

[33]. García-Casal MN, Leets I, Layrisse, M (2000) B-carotene and inhibitors of iron absorption modify iron uptake by Caco-2 cells. J Nutr 130: 5-9.

[34]. Gómez-Ayala AE, Lisbona F, López-Aliaga I, Barrionuevo M, Hartiti S, et al. (1998) The absorption of iron, calcium, phosphorus, magnesium, copper and zinc in the jejunum-ileum of control and iron-deficient rats. Lab Anim 32:72-79.

[35]. Boza J, Sanz Sampelayo MR (1997) Nutritional aspect of goat milk. Anales de la Academia de Ciencias Veterinarias de Andalucía Oriental 10: 109-139.

[36]. Tappenden KA, Thomson AB, Wild GE, McBurney MI (1997) Short-chain fatty acid-supplemented total parenteral nutrition enhances functional adaptation to intestinal resection in rats. Gastroenterology 112: 792-802.

[37]. Díaz-Castro J, Alférez MJM, López-Aliaga I, Nestares T, Campos MS. (2011a) Effect of calcium-fortified milk-rich diets (either goat's or cow's milk) on copper bioavailability in iron-deficient anemia. Dairy Sci Technol 91:203-212.

[38]. Arredondo M, Muñoz P, Mura C, Núñez MT (2003) DMT1, a physiologically relevant apical Cu1 transporter of intestinal cells. Am J Physiol Cell Physiol 284:C1525-C1530.

[39]. Sharp P (2004) The molecular basis of copper and iron interactions. Proc
Nutr Soc 63:563-569.

[40]. Zimnicka AM, Maryon EB, Kaplan JH (2007) Human copper transporter hCTR1 mediates basolateral uptake of copper into enterocytes: implications for copper homeostasis. J Biol Chem 282:26471-26480.

[41]. Domellöf M, Hernell O, Abrams SA, Chen Z, Lönnerdal B (2009) Iron supplementation does not affect copper and zinc absorption in breastfed infants. Am J Clin Nutr 89:185-190.

[42]. Reeves PG, DeMars LCS (2004) Copper deficiency reduces iron absorption and biological half-life in male rats J Nutr 134:1953-1957.

[43]. Reeves PG, Ralston NVC, Idso JP, Lukaski HC (2004) Contrasting and cooperative effects of copper and iron deficiencies in male rats fed different concentrations of manganese and different sources of sulfur amino acids in an AIN-93G-based diet. J Nutr 134: 416-425.

[44]. Turnlund JR (1998) Human whole-body Cu metabolism. Am J Clin Nutr 67:960S-964S.

[45]. Linder MC (1996) Copper. In: Ziegler EE, Filer LJ, editors Present knowledge in nutrition, 7th Ed. International Life Sciences Institute, Washington, pp 307-319.

[46]. Barrionuevo M, Alférez MJM, López-Aliaga I, Sanz Sampelayo MR, Campos MS (2002) Beneficial effect of goat's milk on nutritive utilization of Fe and $\mathrm{Cu}$ in malabsorption syndrome. J Dairy Sci 85:657-664.

[47]. Díaz-Castro J, Pérez-Sánchez LJ, Ramírez López-Frías M, López-Aliaga I Nestares T, et al. (2012) Influence of cow or goat milk consumption on antioxidant defence and lipid peroxidation during chronic iron repletion. Br J Nutr 108:1-8.

[48]. Díaz-Castro J, Ramírez López-Frías M, Campos MS, López-Frías M, Alférez MJ, et al. (2011b) Goat milk during iron repletion improves bone turnover impaired by severe iron deficiency. J Dairy Sci 94:2752-2761.

[49]. Campos MS, Barrionuevo M, Alférez MJM, Nestares T, Diaz-Castro J, et al. (2007) Consumption of caprine milk improves metabolism of calcium and phosphorus in rats with nutritional ferropenic anaemia. Int Dairy J 17:412 419.

[50]. Hale LV, Sells Galvin RJ, Risteli J, Ma YL, et al. (2007) PINP: A serum biomarker of bone formation in the rat. Bone 40: 1103-1109.

[51]. Cosman F, Lindsay R 2004 Therapeutic potential of parathyroid hormone. Curr Osteoporos Rep 2:5-11.

[52]. Langub MC, Monier-Faugere MC, Qi Q, Geng Z, Koszewski NJ, et al. (2001) Parathyroid hormone/parathyroid hormone-related peptide type 1 receptor in human bone J Bone Min Res 16:448-456.

[53]. Bringhurst FR (2002) PTH receptors and apoptosis in osteocytes. J Musculoskelet Neuronal Interact 2:245-251.

[54]. Alférez MJM, López-Aliaga I, Barrionuevo M, Campos MS (2003) Effect of dietary inclusion of goat milk on the bioavailability of zinc and selenium in rats. J Dairy Res 70, 181-187.

[55]. Díaz-Castro J, Alférez MJM, López-Aliaga I, Nestares T, Campos MS (2009) Effect of calcium-supplemented goat or cow milk on zinc status in rats with nutritional ferropenic anaemia. Int Dairy J 19: 116-121.

[56]. Zago MP, Oteiza PI (2001) The antioxidant properties of zinc: interactions with iron and antioxidants. Free Radic Biol Med 31: 266-274.

[57]. Díaz-Castro J, Hijano S, Alférez MJM, López-Aliaga I, Nestares T, et al (2010) Goat milk consumption protects DNA against damage induced by chronic iron overload in anaemic rats. Int Dairy J 20: 495-499.

[58]. Hartwig, A. (2001). Role of magnesium in genomic stability. Mutat Res 465:113-121

[59]. Barzilay G, Mol CD, Robson CN, Walker LJ, Cunningham RP, et al. (1995) Identification of critical active-site residues in the multifunctional human DNA repair enzyme HAP1. Nat Struct Mol Biol 2: 561-568.

[60]. Ban C, Yang W (1998) Crystal structure and ATPase activity of MutL: im plications for DNA repair and mutagenesis. Cell, 95: 541-552.

[61]. Ban C, Junop M, Yang, W (1999) Transformation of MutL by ATP binding and hydrolysis: a switch in DNA mismatch repair. Cell, 97: 85-97.

[62]. Baechtold H, Kuroda M, Sok J, Ron D, Lopez B S, et al. (1999) Human $75 \mathrm{kDa}$ DNA pairing protein is identical to the pro-oncoprotein TLS/FUS and is able to promote D-loop formation. Journal of Biological Chemistry, 274: 34337-34342.

[63]. Bach AC, Babayan UK (1985) Medium-chain triglycerides: an uptake. Am J Clin Nutr, 4: 67-71. 